\title{
Presynaptic NMDA Receptors Modulate Glutamate Release from Primary Sensory Neurons in Rat Spinal Cord Dorsal Horn
}

\author{
Rita Bardoni, ${ }^{1}$ Carole Torsney, ${ }^{2}$ Chi-Kun Tong, ${ }^{2}$ Massimiliano Prandini, ${ }^{1}$ and Amy B. MacDermott ${ }^{2,3}$ \\ ${ }^{1}$ Department of Biomedical Sciences, University of Modena and Reggio Emilia, 41100 Modena, Italy, and ${ }^{2}$ Department of Physiology and Cellular \\ Biophysics and ${ }^{3}$ The Center for Neurobiology and Behavior, Columbia University, New York, New York 10032
}

\begin{abstract}
NMDA receptors have the potential to produce complex activity-dependent regulation of transmitter release when localized presynaptically. In the somatosensory system, NMDA receptors have been immunocytochemically detected on presynaptic terminals of primary afferents, and these have been proposed to drive release of substance $P$ from central terminals of a subset of nociceptors in the spinal cord dorsal horn. Here we report that functional NMDA receptors are indeed present at or near the central terminals of primary afferent fibers. Furthermore, we show that activation of these presynaptic receptors results in an inhibition of glutamate release from the terminals. Some of these NMDA receptors may be expressed in the preterminal axon and regulate the extent to which action potentials invade the extensive central arborizations of primary sensory neurons.
\end{abstract}

Key words: glutamate; spinal cord; pain; presynaptic modulation; patch clamp; primary afferent depolarization

\section{Introduction}

The transfer of sensory input from the periphery to the CNS is critically dependent on the release of glutamate from central terminals of primary afferent fibers within the spinal cord dorsal horn. Regulation of this glutamate release by GABA was the first demonstration of presynaptic inhibition by an endogenous mediator, and it was shown to be attributable to local depolarization at the terminals, or primary afferent depolarization (PAD) (Frank and Fuortes, 1957; Eccles et al., 1961). More recently, modulation of primary afferent glutamate release was demonstrated by exogenous activation of presynaptic AMPA and kainate receptors, likely attributable to the induction of PAD (Kerchner et al., 2001; Lee et al., 2002).

Immunocytochemical studies demonstrate NMDA receptor expression in the cell bodies of both small- and large-diameter sensory neurons (Sato et al., 1993; Liu et al., 1994; Marvizon et al., 2002). In addition, NMDA receptors have been specifically detected within the presynaptic terminals of primary afferent fibers at the electron microscope level (Liu et al., 1994; Lu et al., 2003). Functional NMDA receptor expression on the cell bodies of dorsal root ganglion (DRG) neurons has only been reported rarely (Lovinger and Weight, 1988), despite efforts by others to detect

Received 0ct. 14, 2003; revised Jan. 26, 2004; accepted Jan. 27, 2004.

This work was supported by funding from Ministero dell'Istruzione, dell'Università e della Ricerca (R.B., M.P.) and National Institutes of Health Grants NS040428 and NS029797. We thank Dr. Pier Cosimo Magherini for helpful comments regarding this manuscript.

Correspondence should be addressed to Rita Bardoni, Department of Biomedical Sciences, Section of Physiology, Via Campi, 287, 41100 Modena, Italy. E-mail: bardoni@unimo.it.

DOI:10.1523/JNEUROSCI.4637-03.2004

Copyright $\odot 2004$ Society for Neuroscience $\quad$ 0270-6474/04/242774-08\$15.00/0 functional receptors at the level of the soma and central axons (Agrawal and Evans, 1986; Huettner, 1990).

Activation of presynaptic NMDA receptors has, however, been implicated in the release of substance $\mathrm{P}$ from the central terminals of a subset of nociceptors in the rat dorsal horn. This hypothesis was proposed to account for pain behavior and strong internalization of neurokinin 1 (NK1) receptors in a subpopulation of dorsal horn neurons after intrathecal injection of NMDA in rats (Liu et al., 1997) and for the activity-dependent release of substance $\mathrm{P}$, induced by high-frequency dorsal root stimulation in spinal slices (Marvizon et al., 1997). In other regions of the CNS, such as hippocampus, cerebellum, and enthorinal cortex, immunocytochemical and functional studies have documented presynaptic NMDA receptor expression and their involvement in modulating transmitter release (Pittaluga and Raiteri, 1990; Berretta and Jones, 1996; Cochilla and Alford, 1999; Glitsch and Marty, 1999; Casado et al., 2000, 2002). Although the release of substance $\mathrm{P}$ from a subset of nociceptors is proposed to be regulated by presynaptic NMDA receptors, it is not known whether the release of glutamate, which is thought to be used as a transmitter by all primary afferents (De Biasi and Rustioni, 1988), is regulated by presynaptic NMDA receptor activation.

Here we tested the prediction that primary afferent fibers express functional NMDA receptors. We found that, although functional receptors do not appear to be detectable along the central axon, they are strongly expressed near the central terminals. Moreover, we showed that exogenous activation of these receptors inhibits and slows the synaptic release of glutamate without affecting postsynaptic AMPA receptors. Our data strongly suggests that these presynaptic NMDA receptors have the potential to powerfully influence the transmission of sensory input to the spinal cord dorsal horn. 


\section{Materials and Methods}

Recording from dorsal root and primary afferent terminals. Lumbar and sacral spinal cords with attached dorsal roots were obtained from rats of postnatal day 6 (P6) to P12. The spinal cords were excised and placed in ice-cold oxygenated Krebs' solution $\left[95 \% \mathrm{O}_{2}-5 \% \mathrm{CO}_{2}\right.$ saturated Krebs' solution (in mM): $125 \mathrm{NaCl}, 2.5 \mathrm{KCl}, 26 \mathrm{NaHCO}_{3}, 1.25 \mathrm{NaH}_{2} \mathrm{PO}_{4}, 25$ glucose, $1 \mathrm{MgCl}_{2}$, and $2 \mathrm{CaCl}_{2}$, pH 7.4 (320 mOsm) ]. After removal of the dura mater, all ventral roots were cut close to the cord. Several parallel cuts were made through the spinal cord between L1 and S4 roots, and then the spinal cord sections were hemisected sagittally using a razor blade. After recovery in oxygenated Krebs' solution for at least $1 \mathrm{hr}$ at room temperature, the tissues or isolated roots were placed in a submersion-type recording chamber and superfused continuously with the Krebs' solution at $23-25^{\circ} \mathrm{C}$.

For compound action potential recording, dorsal roots of S1-S4 with DRG attached were transferred to a recording chamber. Two suction electrodes were used: one for electrical stimulation of the root and the other for recording compound action potentials. Electrical stimulation was performed at $0.1-0.2 \mathrm{~Hz}$ for $100 \mu \mathrm{sec}$ using an ISO-Flex Stimulus Isolator (A.M.P.I., Jerusalem, Israel). Experiments were performed at room temperature $\left(23-25^{\circ} \mathrm{C}\right)$ in oxygenated Krebs' solution. To rule out the possibility that the drug had some effect on the DRG itself, a Vaseline barrier was used to separate the compartments of the chamber to isolate the DRG from any contact with drug. Compound action potentials were filtered at $10 \mathrm{kHz}$ and sampled at $20 \mathrm{kHz}$.

The procedure for spinal cord-dorsal root DC depolarization (PAD) recording has been described previously (Lee et al., 2002). Briefly, the tissue was placed across a Vaseline seal to separate the hemisected cord and the dorsal root (see Fig. 1). The Vaseline seal made the drug containing Krebs' solution flow exclusively through the cord without contacting the DRG and increased the output resistance of the dorsal root to magnify the amplitude of the voltage signals. A suction recording electrode was used with an indifferent electrode made of $3 \mathrm{M} \mathrm{NaCl}-3 \%$ agarose as the ground in the same chamber as the cord. DC potential was measured between the indifferent electrode and the root recording electrode. All experiments were performed in low calcium $(20 \mu \mathrm{M})$ and zero magnesium Krebs' solution. Potentials were filtered with a low-pass $10 \mathrm{kHz}$ filter and sampled at $160 \mathrm{~Hz}$. All of the extracellular voltage signals were recorded by a Cygnus ER1 differential amplifier (Cygnus Technology, Delaware Water Gap, PA) or Dagan EX1 differential amplifier (Dagan Corporation, Minneapolis, MI) with a 4001 head stage and stored with the pClamp 6 data acquisition system (Axon Instruments, Union City, CA). Reported peak amplitudes are averages calculated over an $0.6 \mathrm{sec}$ duration. Statistical analysis was performed using repeated measures ANOVA, followed by Newman-Keuls post hoc tests.

Spinal cord slice preparation and stimulation of dorsal roots. Recordings of EPSCs were performed on lamina II neurons in spinal cord slices from postnatal rats (P3-P15). Postnatal rats were anesthetized with halothane and decapitated, and the lumbar region of the spinal cord was removed. The spinal cord was laid down on an agarose block, and transverse slices $(500-600 \mu \mathrm{m})$ with attached dorsal roots were obtained. Slices were incubated in oxygenated Krebs' solution at $35^{\circ} \mathrm{C}$ for $1 \mathrm{hr}$ and used for recording. $95 \% \mathrm{O}_{2}-5 \% \mathrm{CO}_{2}$ saturated Krebs' solution had the following composition (in mM): $125 \mathrm{NaCl}, 2.5 \mathrm{KCl}, 1.25 \mathrm{NaH}_{2} \mathrm{PO}_{4}, 26 \mathrm{NaHCO}_{3}, 25$ glucose, $1 \mathrm{MgCl}_{2}$, and $2 \mathrm{CaCl}_{2}$, $\mathrm{pH} 7.4$ (320 mOsm).

Dorsal roots were stimulated using a glass suction electrode. The stimuli had intensities ranging from $20 \mu \mathrm{A}$ to $10 \mathrm{~mA}$ (constant current stimulus isolation unit output) and durations of $0.05-0.5 \mathrm{msec}$ at a frequency of $0.03-0.05 \mathrm{~Hz}$. Threshold was found by adjusting the intensity from low to high. Once the threshold was identified, the stimulation intensity was adjusted slightly higher than threshold, to avoid synaptic failures in control conditions. Thus, the majority were evoked by low-stimulus intensity and likely to be A fiber, but some (20\%) were of a higher intensity $(>1 \mathrm{~mA})$, likely to be $\mathrm{C}$ fiber. Monosynaptic responses were selected on the basis of the low variability of latency (SD, typically $0.1-0.2 \mathrm{msec}$ ). Polysynaptic responses were identified as responses with more variable latency (SD, $0.7-1.9 \mathrm{msec})$. The reliability of this classification criterion was verified in some cells by stimulating the root at higher frequency ( 1
$\mathrm{Hz}$ ). At this frequency, polysynaptic responses tended to fail and markedly change their latency from one response to the following one.

Patch-clamp recording and analysis. Patch-clamp recording in wholecell configuration was performed on visually identified lamina II neurons at room temperature. Intracellular solution had the following composition (in mM): 130 Cs-gluconate, $10 \mathrm{CsCl}, 11$ EGTA, $1 \mathrm{CaCl}_{2}, 10 \mathrm{HEPES}$, and $2 \mathrm{Mg}^{2+}$-ATP, pH adjusted to 7.2 with $\mathrm{NaOH}$ (osmolarity adjusted to 305 with sucrose). Junction potential was corrected before recording.

Data were recorded and acquired using an Axopatch 1-D amplifier and pClamp 6 software (Axon Instruments). Sampling rate was $10 \mathrm{kHz}$, and data were filtered at $2 \mathrm{kHz}$. The evoked EPSC amplitudes and latencies were detected with Clampfit 6 (Axon Instruments). When the evoked EPSCs presented multiple peaks, the first peak was analyzed by measuring the minimum value within a fixed temporal range $(\sim 2$ $\mathrm{msec}$ ). Evoked EPSC latency was measured as the time interval between the stimulus artifact and the point at which the trace slope started changing significantly (visually determined). Percentage of depression of EPSC peak in NMDA was determined by using average traces and was defined as the following: $\%$ depression $=($ EPSC peak control - EPSC peak $\left._{\text {NMDA }}\right) \times 100 /$ EPSC peak control$_{\text {. }}$.

Significance of evoked EPSC amplitude depression or latency change was determined using an unpaired $t$ test with a two-tailed $p$ value $(p<$ 0.05 was considered significant). The $t$ test was used to compare peak amplitudes or latency changes between samples of 10 traces, obtained in control and in NMDA for each cell individually. The effect of NMDA on peak amplitude and latency change was considered significant in those cells in which the $t$ test produced a significant $p$ value.

Miniature EPSC (mEPSC) amplitudes and frequencies were determined using Minianalysis software (Synaptosoft, Decatur, GA). Detection threshold for mEPSCs was set at 7-10 pA, depending on the amplitude of the membrane noise observed during NMDA application. Significance of miniature EPSC amplitude and frequency changes in NMDA was evaluated using a $t$ test (again, $p<0.05$ was considered significant). When a sufficient number of events was recorded in NMDA, the Kolmogorov-Smirnov test was also applied. The absence of correlation between miniature EPSC frequency or amplitude change in NMDA and the NMDA-induced postsynaptic current (see Fig. 4C,D) was determined by assessing, using a $t$ test, that the parameter $r^{2}$ was not significantly different from zero.

All of the averaged data are expressed as mean \pm SE. Average EPSC traces were obtained from five single traces.

Potassium tail currents were recorded using intracellular solution with the following composition (in $\mathrm{mm}$ ): $130 \mathrm{~K}^{+}$-gluconate, $10 \mathrm{KCl}, 0.1$ $\mathrm{CaCl}_{2}, 1$ EGTA, 10 HEPES, and $2 \mathrm{Mg}^{2+}$-ATP, pH adjusted to 7.2 with $\mathrm{NaOH}$ (osmolarity adjusted to $305 \mathrm{mOsm}$ with sucrose). Tail currents were evoked from a holding potential of $-85 \mathrm{mV}$, after a $20 \mathrm{msec}$ depolarizing step to $+10 \mathrm{mV}$. Leak currents were subtracted using the P4 procedure (Armstrong and Bezanilla, 1974; Bardoni and Belluzzi, 1993). Voltage-dependent $\mathrm{Na}^{+}$and $\mathrm{Ca}^{2+}$ currents were blocked by adding 5 mM QX-314 to the intracellular solution and $0.5 \mathrm{~mm} \mathrm{CdCl}$ to the extracellular solution, respectively. The tail current amplitude was measured after $\sim 2$ msec from the beginning of the hyperpolarizing steps.

Materials. Bicuculline, D-APV, SCH50911, PPADS, NMDA, LY341495, QX-314, and MPPG were purchased from Tocris Cookson (Bristol, UK). TTX was purchased from Alomone Labs (Jerusalem, Israel). Other drugs were obtained from Sigma (St. Louis, MO).

\section{Results}

\section{Functional expression of NMDA receptors by sensory afferents}

Strong depolarization of axons blocks propagation of action potentials. In a study by Agrawal and Evans (1986), kainate depolarized primary afferent axons in dorsal roots and caused depression of $\mathrm{C}$ fiber conduction. In their study, application of $10 \mu \mathrm{M}$ NMDA did not evoke any fiber depolarization, suggesting that no functional NMDA receptors are expressed along primary afferent central axons. However, these experiments did not exclude the possibility that some functional NMDA receptors are located 
A

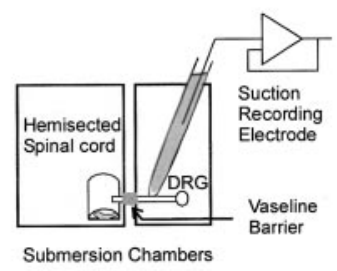

B

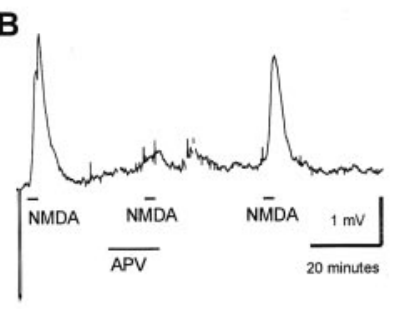

D

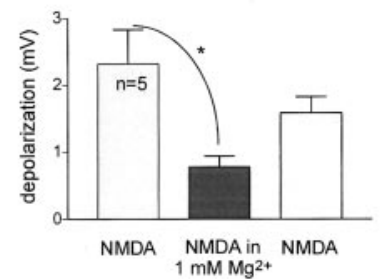

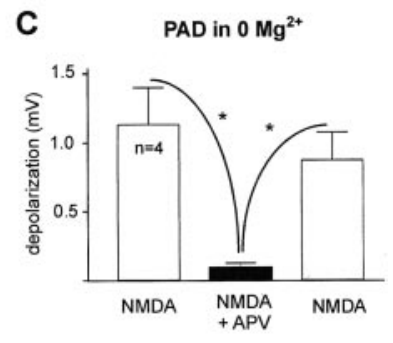

E

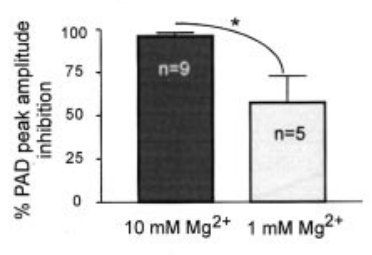

Figure 1. Functional NMDA receptors are expressed near primary afferent terminals. $A$, Schematic drawing of the recording setup. Hemisected spinal cord and the dorsal root were placed across a Vaseline seal. A glass suction electrode was placed on the dorsal root to record primary afferent depolarization. Drugs were only applied to the spinal cord compartment. $B$, The voltage response from primary afferents, or PAD, was recorded from the root. NMDA at 50 $\mu \mathrm{m}$ was able to induce depolarization that was significantly blocked by $50 \mu \mathrm{m} \mathrm{APV}$, indicating that the response was mediated by NMDA receptors. C, The average depolarizations were measured and plotted for each condition indicated under each group of bar graphs. The asterisks represent significant difference based on repeated measures ANOVA, followed by NewmanKeuls post hoc tests $(p<0.05)$. D, NMDA at $50 \mu$ m was able to induce depolarization that was significantly blocked but not abolished by the addition of $1 \mathrm{~mm} \mathrm{Mg}^{2+}$ to the extracellular solution. The average depolarizations were measured and plotted for each condition indicated under each group of bar graphs. The asterisk represents significant difference based on repeated measures ANOVA, followed by Newman-Keuls post hoc tests $(p<0.05)$. E, Bar graph demonstrating the degree of inhibition of NMDA-induced PAD produced by the addition of $1 \mathrm{~mm} \mathrm{Mg}^{2+}$ and $10 \mathrm{~mm} \mathrm{Mg}{ }^{2+}$ to the extracellular solution. The inhibition of NMDA-induced PAD produced by $10 \mathrm{~mm} \mathrm{Mg}{ }^{2+}$ was significantly greater than that produced by $1 \mathrm{~mm} \mathrm{Mg}^{2+}$ (Mann-Whitney $U$ test; $p<0.05)$.

near the central terminals of primary afferent fibers, within the dorsal horn, as suggested by the role of NMDA receptors in mediating substance P release (Liu et al., 1994; Marvizon et al., 1997). By recording from dorsal roots, isolated or attached to the spinal cord, we further investigated possible sites of expression of functional NMDA receptors.

Functional NMDA receptor expression at or near primary afferent central terminals was tested directly by recording PAD from a dorsal root while applying NMDA $(50 \mu \mathrm{M})$ to the attached hemisected spinal cord isolated from the root by a Vaseline gap (Fig. 1A). The hemisected spinal cord was perfused with Krebs' solution containing a low concentration $(20 \mu \mathrm{M})$ of $\mathrm{CaCl}_{2}$ to block any $\mathrm{Ca}^{2+}$-dependent release of transmitters. This bath was sufficient to completely block dorsal root-evoked dorsal root potentials within $5 \mathrm{~min}$. NMDA ( $50 \mu \mathrm{M})$ routinely evoked a depolarization of the afferent fibers or PAD $(1.1 \pm 0.27 \mathrm{mV} ; n=4)$. This depolarization was mediated by NMDA receptors because it

was significantly blocked by $50 \mu \mathrm{M}$ D-APV (Fig. $1 B, C)(92 \%$ depression; $n=4 ; p<0.05$ ). This observation suggests that functional NMDA receptors are indeed expressed at or near the presynaptic terminals of primary afferent fibers.

NMDA was applied to isolated dorsal roots from postnatal rats while compound action potentials were stimulated and recorded. Application of $100 \mu \mathrm{M}$ NMDA failed to cause any change in the afferent volley evoked by root stimulation (data not shown; $n=6$ ). In similar experiments, kainate and capsaicin selectively inhibited the slow volley (Agrawal and Evans, 1986; Labrakakis et al., 2003). Neither fast- nor slow-conducting fiber volleys showed NMDA sensitivity, demonstrating that central primary afferent axons lack functional NMDA receptor expression or that axonal NMDA receptors do not have good access to applied NMDA.

Interestingly, NMDA-induced PAD was still observed, although significantly reduced, when $1 \mathrm{mM} \mathrm{Mg}^{2+}$ was included in the extracellular solution ( $57 \%$ depression; $n=5)($ Fig. $1 D)$. This suggests that NMDA receptors expressed on primary afferent terminals are not completely blocked by magnesium ions at the resting membrane potential. Almost complete inhibition of NMDA-induced PAD was obtained in the presence of $10 \mathrm{~mm}$ extracellular $\mathrm{Mg}^{2+}$ (96\% depression; $\left.n=9\right)$ (Fig. 1E).

\section{NMDA receptor-mediated modulation of glutamate release}

The PAD evoked by NMDA suggests that NMDA receptors are near primary afferent central terminals. These receptors are well located to modulate primary afferent fiber excitability and regulate release of glutamate at synapses with dorsal horn neurons (Liu et al., 1994; Lu et al., 2003). We therefore investigated the modulatory effect of NMDA application on AMPA receptormediated EPSCs, recorded from spinal cord lamina II neurons from postnatal rats (P6-P15) (Fig. 2A,B). Monosynaptic EPSCs were evoked by dorsal root stimulation and recorded at a frequency of $0.03-0.05 \mathrm{~Hz}$. Membrane potential was held at -85 $\mathrm{mV}$ under voltage clamp to minimize current flow through activated NMDA receptors on the postsynaptic neuron. All of the experiments on spinal cord slices were performed in $10 \mu \mathrm{M}$ bicuculline and $5 \mu \mathrm{M}$ strychnine to block the inhibitory inputs mediated by $\mathrm{GABA}_{\mathrm{A}}$ and glycine receptors and to isolate AMPA receptor-mediated EPSCs.

Bath application of NMDA $(10,25$, and $50 \mu \mathrm{M})$ rapidly caused an increase in spontaneous synaptic activity and a depression of AMPA EPSC peak amplitude. Both of these effects were reversible after wash. In most neurons tested, NMDA caused a significant decrease of peak EPSC amplitude $(p<0.05)$; the mean percentage depression within this group of neurons was $47.6 \pm$ $15.6 \%$ in $10 \mu \mathrm{M}$ NMDA ( $n=4$ of 5), $45.8 \pm 8.5 \%$ in $25 \mu \mathrm{M}$ NMDA ( $n=3$ of 4$)$, and $76 \pm 7.3 \%$ in $50 \mu \mathrm{M} \mathrm{NMDA} \mathrm{(} n=5$ of 5$)$ (Fig. 2C). The application of NMDA at different concentrations also resulted in synaptic failures in the majority of lamina II neurons tested ( $n=9$ of 14) (Fig. 2D). The inhibition of AMPA EPSC amplitude induced by NMDA was significantly decreased when $50 \mu \mathrm{M}$ D-APV was added to $50 \mu \mathrm{M}$ NMDA $(n=3$; $p<$ 0.01 ), confirming that depression of AMPA EPSC peak was mediated by NMDA receptors (Fig. $2 C$ ). We observed a significant NMDA-induced depression of AMPA EPSC amplitudes evoked by both low stimulus intensities (in the A fiber range) and high intensities (in the $\mathrm{C}$ fiber range). There was no correlation between the magnitude of depression and the stimulation intensity, consistent with immunohistochemical observations of NMDA receptor subunit expression in large numbers of both A- and C-type neurons in dorsal root ganglia (Marvizon et al., 2002).

Although membrane potential was held negative to resting 
A

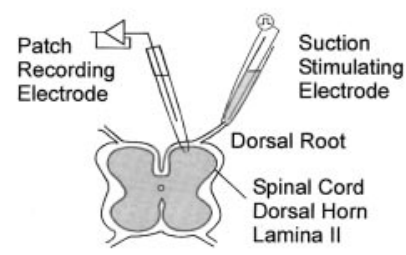

B
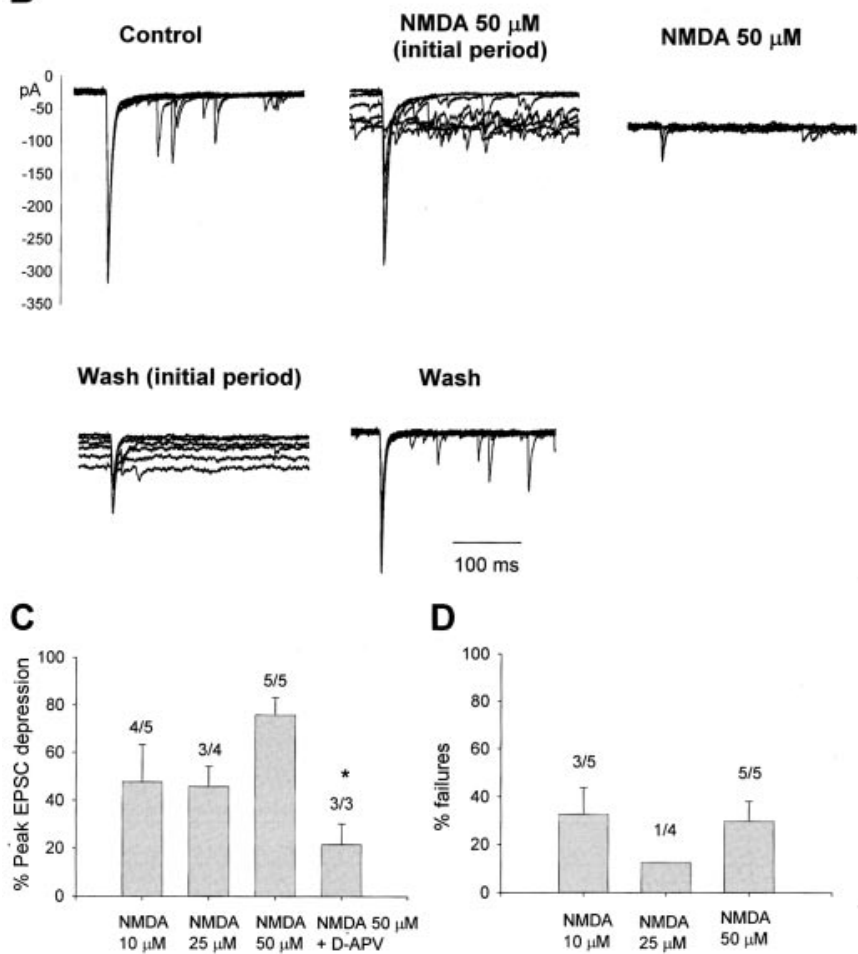

Figure 2. NMDA application causes a depression of evoked AMPA receptor-mediated EPSCS in lamina II neurons and induces synaptic failures. $A$, Schematic drawing of the recording setup. $B$, AMPA receptor-mediated EPSC recorded from a lamina II neuron, held at $-85 \mathrm{mV}$, obtained from a $\mathrm{P} 11$ rat. NMDA at $50 \mu \mathrm{m}$ rapidly caused a significant depression of AMPA EPSC amplitude, initial increase and later decrease of spontaneous activity, and the appearance of synaptic failures, and produced a constant postsynaptic current. $C$, Inhibitory effect of 10,25 , and $50 \mu \mathrm{m}$ NMDA expressed as mean percentage of AMPA EPSC peak amplitude depression. The application of $50 \mu \mathrm{M}$ D-APV significantly antagonized the depressant effect of $50 \mu \mathrm{M}$ NMDA ( $p<$ 0.01). Numbers above the bars represent the number of cells with significant depression over the total number of tested cells. D, Histogram showing the percentage of synaptic failures induced by 10,25 , and $50 \mu \mathrm{m}$ NMDA on AMPA EPSCs. Numbers above the bars represent the number of cells in which synaptic failures were observed over the total number of tested cells.

potential $(-85 \mathrm{mV})$, which should be sufficient to maintain the $\mathrm{Mg}^{2+}$ blockade of NMDA receptors, the application of NMDA produced a constant increase of the negative holding current in all tested cells $(n=40)$ (Fig. $3 B)$. The mean amplitude of this inward current in the postsynaptic neuron was dose dependent and significantly reduced in the presence of $50 \mu \mathrm{M} \mathrm{D}-\mathrm{APV}(n=6$; $p<0.05$ ) (Fig. $3 B$ ). The $I-V$ curve, obtained by plotting the amplitude of the NMDA-evoked inward current as a function of different holding potentials, showed the typical J-shape of NMDA receptor-mediated currents $(n=3)$ (Fig. 3A). However, in contrast with the voltage dependence exhibited by some synaptic NMDA receptors in the dorsal horn (Bardoni et al., 1998), the $I-V$ relationships obtained with agonists applied to lamina II neurons showed a significant amount of current at negative membrane potentials. This would indicate that these dorsal horn
A

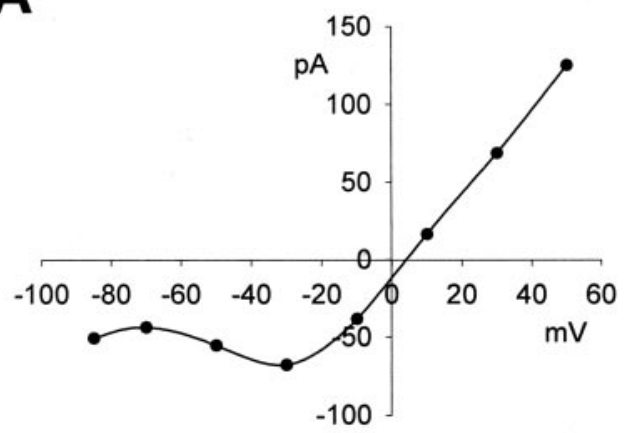

B

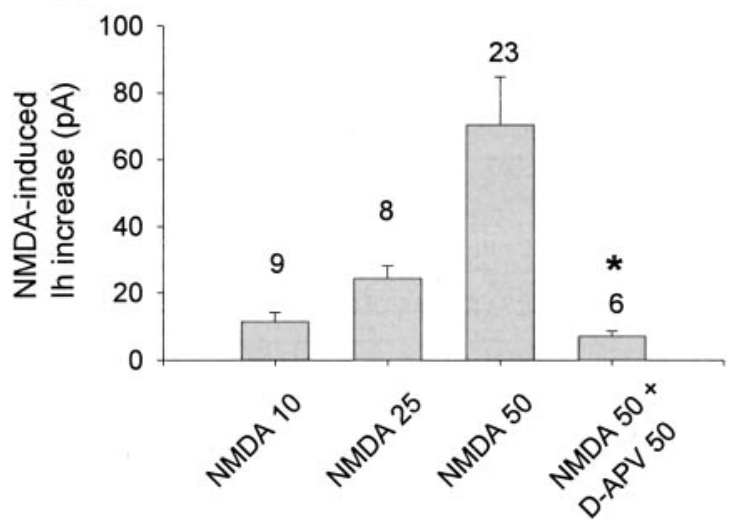

Figure 3. NMDA application evokes a dose-dependent, NMDA receptor-mediated wholecell current in lamina II neurons. $A$, The amplitude of the change in holding current, recorded in the presence of $50 \mu \mathrm{m} N M D A$, is plotted as function of membrane potential. Each value represents the average of 10 traces recorded from a lamina II neuron from a P3 rat. The $I-V$ curve shows the characteristic J-shape of NMDA receptors. $B$, Mean amplitude of the increase in holding current, recorded at $-85 \mathrm{mV}$, in the presence of 10,25 , and $50 \mu \mathrm{m}$ NMDA. The amplitude of the current evoked by NMDA is dose dependent and significantly depressed by the application of D-APV $(p<0.05)$. Numbers on top of each bar represent the number of cells tested in each condition.

neurons expressed NMDA receptors, either postsynaptically or extrasynaptically, that were tonically activated during NMDA application and were weakly blocked by magnesium ions.

The presence of a constant postsynaptic current during the application of NMDA might suggest that the NMDA-induced depression of AMPA EPSC amplitude was attributable to a postsynaptic effect. To test this possibility, we measured the effect of NMDA on the amplitudes of AMPA receptor-mediated mEPSCs recorded from lamina II neurons in the presence of $0.5 \mu \mathrm{M}$ TTX, $10 \mu \mathrm{M}$ bicuculline, and $5 \mu \mathrm{M}$ strychnine. As shown in Figure $4, A$ and $B$, application of $25 \mu \mathrm{M}$ NMDA did not cause significant depression of mEPSC amplitude. Furthermore, there was no correlation between the mEPSC amplitude change, obtained from 11 lamina II neurons in NMDA (seven in $50 \mu \mathrm{M}$ NMDA and four in $25 \mu \mathrm{M}$ NMDA), and the amplitude of NMDA-induced holding current increase $\left(r^{2}=0.149 ; p>0.05\right)$ (Fig. $\left.4 D\right)$, suggesting that a postsynaptic mechanism was not the predominant cause of evoked AMPA EPSC depression observed in NMDA.

Application of $50 \mu \mathrm{M}$ NMDA caused a significant decrease of mEPSC frequency in most cells (five of seven; data not shown). At this concentration, however, we were able to obtain full recovery only in one neuron. The application of a lower concentration of NMDA $(25 \mu \mathrm{M})$ still produced a significant decrease of mEPSC frequency in all tested neurons, followed by a complete recovery 
A
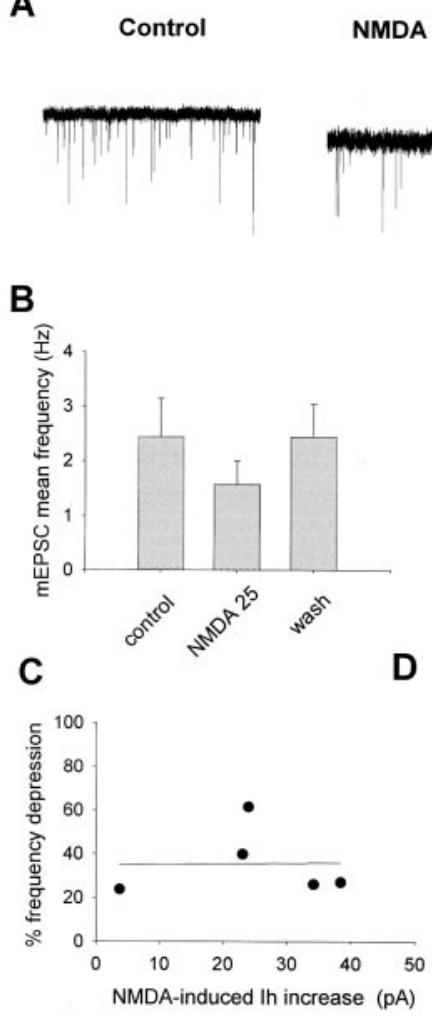

Wash
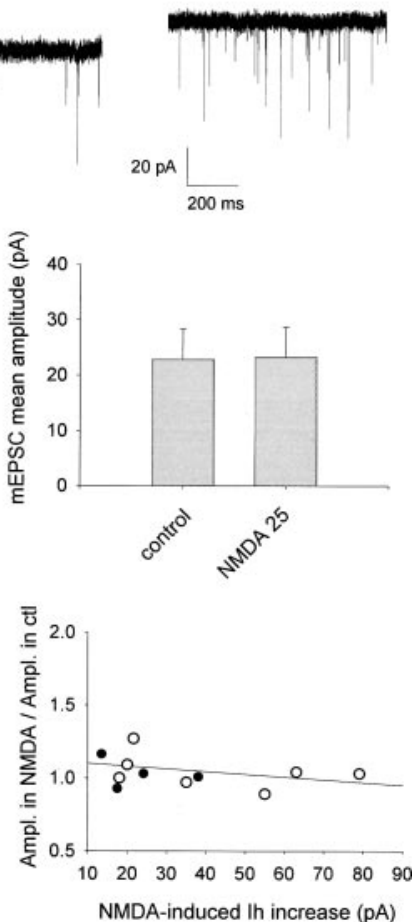

Figure 4. NMDA application significantly depresses mEPSC frequency but does not cause any significant change of $\mathrm{mEPSC}$ amplitude. $A$, Examples of $\mathrm{mEPSC}$ recorded from a P9 lamina II neuron in control, $25 \mu \mathrm{M} \mathrm{NMDA}$, and wash. Recordings were obtained at $-85 \mathrm{mV}$, in the constant presence of $0.5 \mu \mathrm{M}$ TTX. NMDA application depresses mEPSC frequency without affecting the amplitude. $B$, Histograms showing the effect of $25 \mu \mathrm{m}$ NMDA on mEPSC mean frequency (left; $n=5$ ) and on mEPSC mean amplitude (right; $n=4$ ). The mean frequency was significantly depressed (paired $t$ test; $p<0.05$ ), whereas the mean amplitude was unchanged (paired $t$ test; $p>0.05$ ). C, The percentage of mEPSC frequency depression in $25 \mu \mathrm{M}$ NMDA is represented as a function of the NMDA-induced holding current increase. There is no significant correlation between the two parameters $\left(r^{2}=0.0003 ; p>0.05\right)$. $D$, The graph represents the ratios between the mean values of $\mathrm{mEPSC}$ amplitude, obtained from 11 lamina II neurons (filled circles, $25 \mu \mathrm{m} \mathrm{NMDA}$; open circles, $50 \mu \mathrm{M} \mathrm{NMDA}$ ) and in control, plotted as a function of the NMDA-induced holding current increase. There is no significant correlation between the two parameters $\left(r^{2}=0.149 ; p>0.05\right)$.

$(n=5)$ (Fig. $4 A, B)$. The depression of mEPSC frequency caused by $25 \mu \mathrm{M}$ NMDA was not accompanied by any significant change of mEPSC amplitude $(n=4)$ (Fig. $4 B)$, and there was also no significant correlation between depression of mEPSC frequency and the amplitude of NMDA-induced holding current increase $\left(r^{2}=0.0003 ; p>0.05 ; n=5\right)$ (Fig. 4C). A decrease in mEPSC frequency with no change in amplitude points to a likely presynaptic site of action of NMDA.

Because NMDA application in the presence of TTX produces a depression of mEPSC frequency, the increase in spontaneous activity, observed when TTX is absent, may be attributable to action potential firing of dorsal horn neurons or primary afferent terminals, after depolarization induced by NMDA. This hypothesis is supported by the presence of the NMDA-induced inward current in postsynaptic neurons, even at very negative membrane potentials. This also raises the possibility that NMDA receptormediated depolarization of dorsal horn neurons might induce the release of neurotransmitters capable of inhibiting glutamate release from primary afferent terminals. To probe the potential involvement of intraspinal circuits in the AMPA EPSC depression, we applied NMDA in the presence of a mixture of antago-

A

\section{Cocktail \\ Cocktail + NMDA $50 \mu \mathrm{M}$ \\ Wash}
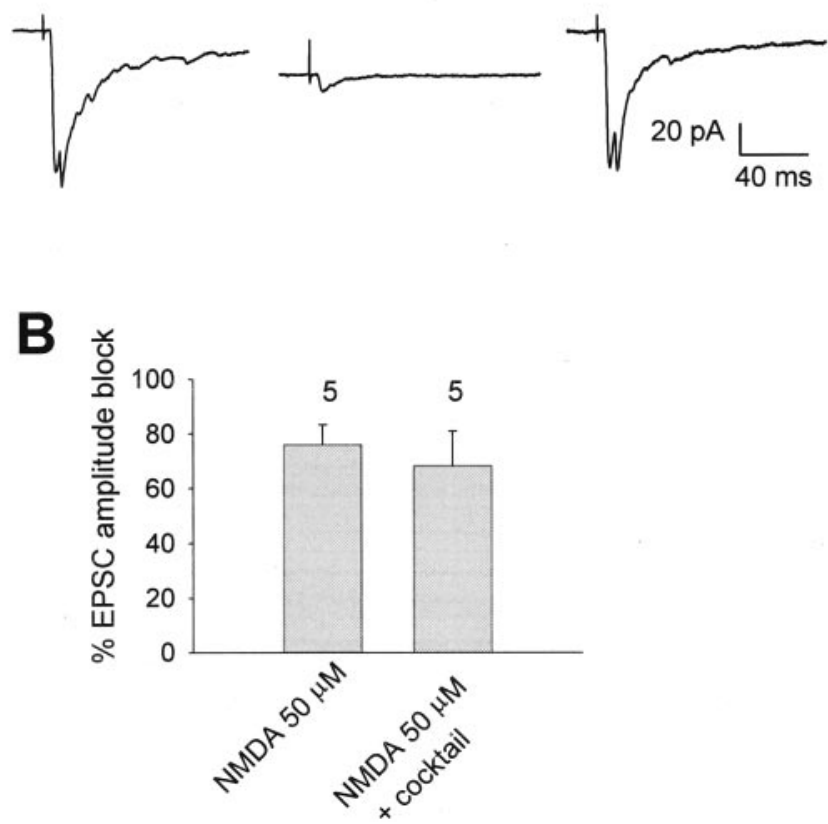

Figure 5. AMPA EPSC depression mediated by presynaptic NMDA receptors is not significantly attributable to activation of dorsal horn interneurons. $A$, Average traces of AMPA EPSCS recorded at $-85 \mathrm{mV}$ from a lamina II neuron from a P11 rat, in a mixture (Cocktail) containing $20 \mu \mathrm{m} S C H 50911,50 \mu \mathrm{m}$ PPADS, $10 \mu \mathrm{m}$ DPCPX, $25 \mu \mathrm{m}$ LY341495, and $100 \mu \mathrm{m}$ MPPG (bicuculline and strychnine are also included). The application of $50 \mu \mathrm{m}$ NMDA was still able to induce a significant depression of AMPA EPSC amplitude. $B$, The histogram compares the mean percentage of AMPA EPSC depression in $50 \mu \mathrm{m}$ NMDA alone with the depression in $50 \mu \mathrm{m}$ NMDA plus mixture. The amount of depression obtained in NMDA plus mixture is not significantly different from the inhibition obtained in NMDA alone (unpaired $t$ test; $p>0.05$ ). Numbers above each bar represent the number of tested cells.

nists to receptors potentially present on primary afferent terminals. These include the following (in $\mu \mathrm{M}$ ): 10 DPCPX, 20 SCH50911, 50 PPADS, 25 LY341495, and 100 MPPG, blocking $A_{1}, G A B A_{B}, P_{2 x}$, and metabotropic glutamate receptors, respectively. Bicuculline $(10 \mu \mathrm{M})$ and strychnine $(5 \mu \mathrm{M})$ were always present. In the presence of this antagonist mixture, $50 \mu \mathrm{M}$ NMDA was still able to significantly depress the evoked AMPA EPSCs (Fig. $5 A, B$ ) in a manner similar to NMDA alone. Thus, our data support the hypothesis that NMDA directly activates NMDA receptors expressed on primary afferent terminals and decreases glutamate release, although the possibility remains that an endogenous mediator of synaptic depression is involved for which we have not tested.

Tonic activation of dorsal horn neurons by applied NMDA is likely to cause accumulation of $\mathrm{K}^{+}$in the tissue. Potassium ions enhance or depress transmitter release in some preparations, depending on the concentration (Schmitz et al., 2001). Therefore, it is possible that NMDA-induced $\mathrm{K}^{+}$accumulation is responsible for the depression of the evoked EPSC amplitude by NMDA. To address this possibility, we estimated the increase of extracellular $[\mathrm{K}]_{\mathrm{o}}$ induced by $50 \mu \mathrm{M}$ NMDA using the equilibrium potential of potassium tail currents recorded from lamina II neurons, evoked by a test pulse to $+10 \mathrm{mV}$. NMDA application caused a decrease of the potassium equilibrium potential by $9.3 \pm 3.2 \mathrm{mV}$, corresponding to an average $[\mathrm{K}]_{\mathrm{o}}$ increase of $1.2 \pm 0.3 \mathrm{mM}(n=3$; data 


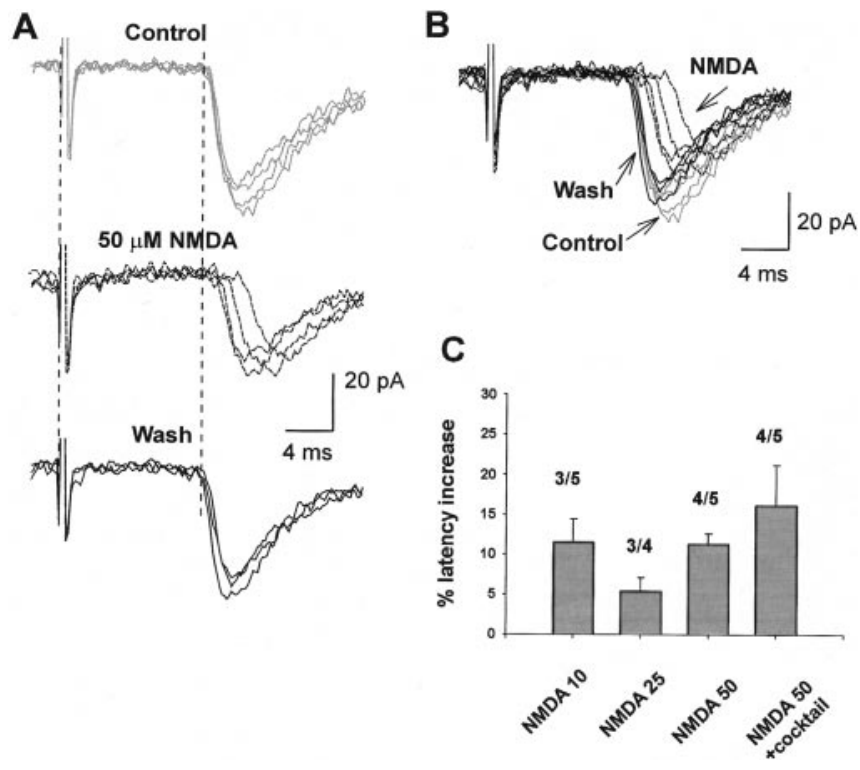

Figure 6. Activation of NMDA receptors on primary afferents increases the latency of monosynaptic AMPA EPSCS. A, AMPA EPSCs recorded at $-85 \mathrm{mV}$ from a lamina II neuron from a P11 rat. NMDA at $50 \mu \mathrm{m}$ significantly prolonged the response latency. $B$, Same as in $A$, but all traces are superimposed (control, gray; NMDA, dashed line; wash, black). C, Summary of the NMDA effect on EPSC latency, tested at different concentrations and in mixture (Cocktail). Numbers on top of each bar represent the number of cells in which the latency shift was significant over the total number of cells tested.

not shown). Because our normal $[\mathrm{K}]_{\mathrm{o}}$ is $2.5 \mathrm{~mm}$, application of 50 $\mu \mathrm{M}$ NMDA would raise total $[\mathrm{K}]_{\mathrm{o}}$ to $\sim 4 \mathrm{~mm}$. This is in the range of $[\mathrm{K}]_{\mathrm{o}}$ causing enhanced transmitter release in the study by Schmitz et al. (2001). Furthermore, previous studies on isolated spinal cord preparations have shown that an increase of $[\mathrm{K}]_{\mathrm{o}}$ up to $5.5 \mathrm{~mm}$ does not significantly depress dorsal root potential and reflex amplitudes (Czèh et al., 1988), whereas an extracellular potassium elevation up to $8 \mathrm{~mm}$ is able to increase the efficacy of transmission evoked by dorsal root stimulation (Nicoll, 1979). These considerations exclude extracellular potassium accumulation as a major contributor to the NMDA-mediated synaptic depression.

\section{NMDA receptors on preterminal axons of primary afferents}

NMDA receptors functionally expressed near primary afferent central terminals could mediate synaptic depression by several mechanisms. Depolarization of primary afferent fibers near the nerve terminals by presynaptic NMDA receptor activation could depress action potential-evoked glutamate release by interfering with action potential firing and propagation along the presynaptic axon. This hypothesis is supported by the observation that NMDA application causes a reversible increase in latency of monosynaptic AMPA EPSCs recorded from spinal cord slices (Fig. $6 A, B$ ). The application of 10,25 , or $50 \mu \mathrm{M}$ NMDA induced a significant shift of latency to onset of the synaptic current in most dorsal horn neurons that was prevented by $50 \mu \mathrm{M}$ D-APV (data not shown). The latency increase was still present in the mixture of antagonists used to test for indirect effects of NMDA in the evoked EPSC experiments (mean percentage increase in latency: $10 \mu \mathrm{M}$ NMDA, $11.5 \pm 2.9 \%, n=3$ of $5 ; 25 \mu \mathrm{M}$ NMDA, $5.4 \pm 1.7 \%, n=3$ of $4 ; 50 \mu \mathrm{M} \mathrm{NMDA}, 11.3 \pm 1.3 \%, n=4$ of $5 ; 50$ $\mu \mathrm{M}$ NMDA plus mixture, $16.2 \pm 5 \%, n=4$ of 5 ) (Fig. $6 C$ ). Most dorsal horn neurons ( 13 of 17) showed both a significant depression of monosynaptic AMPA EPSC and an increase in synaptic latency. The effect of NMDA on synaptic latency, which is mostly determined by the propagation of action potentials along the presynaptic axon, strongly suggests that NMDA receptors expressed near the presynaptic terminals can interfere with the transmission of action potentials along primary afferent axons.

\section{Discussion}

We showed that NMDA receptors are functionally expressed near central terminals of primary afferent fibers in postnatal rat spinal cord dorsal horn. Their activation produces a depolarization of primary afferent fibers, even in the presence of $1 \mathrm{mM} \mathrm{Mg}^{2+}$. Activation of these NMDA receptors causes depression of action potential-evoked glutamate release accompanied by an increase in failure of transmitter release from primary afferent fibers onto lamina II neurons and an increase in synaptic latency, suggesting that at least part of the inhibition is attributable to slowing and suppression of axonal action potentials in the preterminal membrane. However, NMDA receptors are both depolarizing and permeable to $\mathrm{Ca}^{2+}$. Thus, modulation of the release machinery by presynaptic NMDA receptors could also be involved in the synaptic depression.

\section{Subcellular localization of NMDA receptors on sensory neurons}

Several immunohistochemical and molecular studies have shown NMDA receptor expression at the level of DRG somata. A high percentage of DRG neurons have been reported to express the NR1 subunit (Sato et al., 1993; Liu et al., 1994; Coggeshall and Carlton, 1998; Marvizon et al., 2002). NR2 subunits have also been detected, particularly NR2B and NR2D (Ma and Hargreaves, 2000; Marvizon et al., 2002). We observed significant NMDA-induced depression of AMPA EPSCs in most lamina II neurons tested, consistent with the widespread expression pattern of presynaptic NMDA receptors on DRG neurons. NMDA receptors are present on both A- and C-type primary afferents (Marvizon et al., 2002), although the presynaptic NR1 subunit seems to be mainly expressed on myelinated, mechanosensitive fibers (Lu et al., 2003). In our experiments on spinal cord slices, most AMPA EPSCs were evoked by low-intensity stimulation and were probably mediated by myelinated A-type fibers. However, in a small percentage of neurons $(\sim 20 \%)$, stimulation thresholds were quite high $(>1 \mathrm{~mA})$, suggesting that $\mathrm{C}$ fibers could be involved. NMDA-induced depression of EPSC amplitude, however, did not correlate with stimulus intensity.

The subcellular localization of functional NMDA receptors on DRG neurons has been a matter of debate for some time. Only one electrophysiological study has described NMDA receptormediated current in a substantial proportion of DRG neurons held at resting potential (Lovinger and Weight, 1988) (but see Huettner, 1990). Extracellular recordings from the isolated dorsal roots failed to show any depolarization in response to NMDA (Agrawal and Evans, 1986). In our experiments, NMDA did not affect the propagation of the afferent volley along primary afferent central axons in isolated dorsal root, whereas application of NMDA to hemisected spinal cords, recorded in low $\mathrm{Ca}^{2+}$ bath to block internal synaptic circuits, resulted in depolarization of the primary afferent fibers. This indicates that NMDA receptors are expressed on or near the central terminals of the afferents. In agreement with this observation, electron microscopy has revealed that a high percentage of glutamatergic synapses in superficial dorsal horn express NMDA receptors at presynaptic terminals (Liu et al., 1994; Lu et al., 2003). 
NMDA receptor activation in the presence of $\mathrm{Mg}^{2+}$

We observed depolarization of primary afferent axon terminals and depression of EPSC amplitude in the presence of $1 \mathrm{~mm}$ extracellular $\mathrm{Mg}^{2+}$. At the DRG neuron resting potential of approximately $-60 \mathrm{mV}$ (Waddell and Lawson, 1990), NMDA receptors composed of NR1 and NR2A and/or NR2B are more strongly blocked by $\mathrm{Mg}^{2+}$ than receptors expressing the NR2D subunit (Monyer et al., 1994). Thus, our data indicate that the NR2D subunit may be an important constituent of these presynaptic NMDA receptors, as shown for presynaptic NMDA receptors in hippocampus (Thompson et al., 2002). However, it may be that, at $-60 \mathrm{mV}$, there would be sufficient remaining current through NR1 and NR2A/B to relieve the $\mathrm{Mg}^{2+}$ block, resulting in membrane depolarization and further unblocking of other NMDA receptors.

NMDA also induced an increase in holding current in lamina II dorsal horn neurons in the presence of $1 \mathrm{mM} \mathrm{Mg}^{2+}$. The current-voltage relationship of this postsynaptic current had a negative slope conductance as is typical of NMDA receptors. However, the current amplitude, dependent on NMDA concentration, was substantial even at the holding potential of $-85 \mathrm{mV}$, implying that it is sustained by NMDA receptors having a low sensitivity to $\mathrm{Mg}^{2+}$. Extrasynaptic NMDA receptors containing the NR2D subunit, reported in dorsal horn neurons by Momiyama (2000), could be involved in the generation of the postsynaptic current observed during NMDA application.

\section{Mechanism of NMDA receptor modulation of glutamatergic transmission}

NMDA caused a depression of peak amplitude and an increase in synaptic latency and failures of evoked monosynaptic AMPA EPSCs in most lamina II neurons. Our data suggest that this synaptic inhibition is attributable to a presynaptic mechanism, directly mediated by NMDA receptors.

Presynaptic NMDA receptors could depress evoked release by decreasing the input resistance of the afferent terminal, shunting the propagation of incoming action potentials (Segev, 1990). NMDA receptors could also substantially depolarize the afferent axons to inactivate $\mathrm{Na}^{+}$channels (Graham and Redman, 1994). Both mechanisms would produce either a depression of action potential amplitude, causing a decrease of glutamate release, or a complete block of action potential propagation, causing the appearance of synaptic failures. $\mathrm{Na}^{+}$channel inactivation could also be responsible for the slowing of action potential propagation, resulting in an increase of synaptic latency. Finally, the activation of presynaptic NMDA receptors could inhibit evoked synaptic transmission by causing the inactivation of voltagedependent $\mathrm{Ca}^{2+}$ channels; this would affect the level of $\mathrm{Ca}^{2+}$ inside the terminal and, indirectly, interfere with the release machinery.

NMDA receptors are permeable to $\mathrm{Ca}^{2+}$. This property underlies the facilitating effect that NMDA receptor activation has on glutamate release as a result of $\mathrm{Ca}^{2+}$ entry through presynaptic NMDA receptors (Cochilla and Alford, 1999; Glitsch and Marty, 1999). However, rather than an increase in mEPSC frequency being induced by $25 \mu \mathrm{M}$ NMDA in our experiments, a decrease was observed. If the NMDA receptors are predominantly localized in the preterminal membrane, the $\mathrm{Ca}^{2+}$ entering the cells through the receptors might not reach into the terminals. Presynaptic NMDA receptors might activate a second-messenger pathway, as shown in the cerebellum (Casado et al., 2000), leading to the modulation of voltage-dependent channels or of other components involved in synaptic release. However, the decrease in mEPSC frequency may not be associated with the same terminals stimulated in the evoked release studies, the primary afferent terminals, but instead could be associated with other glutamatergic terminals forming synapses on the neurons under study.

The effect of presynaptic NMDA receptors on glutamate release in lamina II is paradoxically opposite to the facilitating action of NMDA on substance P release (Marvizon et al., 1997). In this study of substance P release, $100 \mu \mathrm{M}$ NMDA was used, a concentration that in our preparation caused such strong activation of NMDA receptors on dorsal horn neurons that it was difficult to observe any presynaptic effects. It is possible that the higher concentration of NMDA used in that study produces a strong depolarization of the terminal, unblocking other NMDA receptors and causing substantial $\mathrm{Ca}^{2+}$ entry into the terminal with subsequent substance $\mathrm{P}$ release. Substance $\mathrm{P}$ may also be released under our experimental conditions. However, the depressant effect of NMDA on evoked EPSC amplitude is unlikely to be directly attributable to the action of substance $\mathrm{P}$ because NK1 receptor activation potentiates evoked EPSC amplitude instead of depressing it (Ikeda et al., 2003).

\section{Physiological role of NMDA receptor-mediated regulation of glutamate}

Although many of the presynaptic terminals contacting primary afferents in the dorsal horn seem to be GABAergic (Alvarez, 1998), a recent study reports the presence of glutamatergic synaptic contacts on primary afferents in frog spinal cord, likely formed by glutamatergic interneurons (Vesselkin et al., 2003). Furthermore, NMDA receptor subunit NR1 has been detected on several primary afferent terminals at the center of glomerular structures in inner lamina II (Lu et al., 2003). Given that glomeruli are the proposed morphological basis for modulation of primary afferent input (Willis and Coggeshall, 1991), this suggests that these presynaptic NMDA receptors could be endogenously activated synaptically and modulate sensory throughput.

Endogenous activation of presynaptic NMDA receptors could also occur through glutamate spillover. Russo et al. (2000), working in the turtle spinal cord, reported dorsal root potentials mediated by $\mathrm{GABA}_{\mathrm{A}}$, non-NMDA, and NMDA receptors that are reduced, but not blocked, in the presence of tetrodotoxin, indicating that TTX-insensitive primary afferents may drive release of transmitters onto other primary afferent terminals. Glutamate released by primary afferent fibers could activate NMDA receptors expressed on the same or on nearby terminals, depolarize them, and control the subsequent release of glutamate during repetitive stimulation. Kainate receptors have been proposed to have this type of autoreceptor function on mossy fiber terminals in the hippocampus (Kamiya et al., 2002). The high affinity of NMDA receptors for glutamate and their ability to depolarize the terminals in the presence of physiological concentrations of $\mathrm{Mg}^{2+}$ suggests that presynaptic NMDA receptors could act as sensors and fine modulators of primary afferent fiber activity. The role of second-messenger pathways in NMDA receptormediated modulation of glutamate release by primary afferent fibers remains to be investigated.

\section{References}

Agrawal SG, Evans RH (1986) The primary afferent depolarizing action of kainate in the rat. Br J Pharmacol 87:345-355.

Alvarez FJ (1998) Anatomical basis for presynaptic inhibition of primary sensory fibers. In: Presynaptic inhibition and neural control (Rudomin P, Romo R, Mendell LM, eds), pp 13-50. New York: Oxford UP.

Armstrong CM, Bezanilla F (1974) Charge movement associated with the 
opening and closing of the activation gates of Na channels. J Gen Physiol 63:533-552.

Bardoni R, Belluzzi O (1993) Kinetic study and numerical reconstruction of A-type current in granule cells of rat cerebellar slices. J Neurophysiol 6:2222-2231.

Bardoni R, Magherini PC, MacDermott AB (1998) NMDA EPSCs at glutamatergic synapses in the spinal cord dorsal horn of the postnatal rat. J Neurosci 18:6558-6567.

Berretta N, Jones RS (1996) Tonic facilitation of glutamate release by presynaptic $N$-methyl-D-aspartate autoreceptors in the entorhinal cortex. Neuroscience 75:339-344.

Casado M, Dieudonne S, Ascher P (2000) Presynaptic N-methyl-Daspartate receptors at the parallel fiber-Purkinje cell synapse. Proc Natl Acad Sci USA 97:11593-11597.

Casado M, Isope P, Ascher P (2002) Involvement of presynaptic N-methylD-aspartate receptors in cerebellar long-term depression. Neuron 3:123-130.

Cochilla AJ, Alford S (1999) NMDA receptor-mediated control of presynaptic calcium and neurotransmitter release. J Neurosci 19:193-205.

Coggeshall RE, Carlton SM (1998) Ultrastructural analysis of NMDA, AMPA, and kainate receptors on unmyelinated and myelinated axons in the periphery. J Comp Neurol 391:78-86.

Czèh G, Obih JCA, Somjen GG (1988) The effect of changing extracellular potassium concentration on synaptic transmission in isolated spinal cords. Brain Res 446:50-60.

De Biasi S, Rustioni A (1988) Glutamate and substance P coexist in primary afferent terminals in the superficial laminae of spinal cord. Proc Natl Acad Sci USA 85:7820-7824.

Eccles JC, Eccles RM, Magni F (1961) Central inhibitory action attributable to presynaptic depolarization produced by muscle afferent volleys. J Physiol (Paris) 159:147-166.

Frank K, Fuortes MGF (1957) Presynaptic and postsynaptic inhibition of monosynaptic reflexes. Fed Proc 16:39-40.

Glitsch M, Marty A (1999) Presynaptic effects of NMDA in cerebellar Purkinje cells and interneurons. J Neurosci 19:511-519.

Graham B, Redman SA (1994) Simulation of action potentials in synaptic boutons during presynaptic inhibition. J Neurophysiol 71:538-549.

Huettner JE (1990) Glutamate receptor channels in rat DRG neurons: activation by kainate and quisqualate and blockade of desensitization by Con A. Neuron 5:255-266.

Ikeda H, Heinke B, Ruscheweyh R, Sandkuhler J (2003) Synaptic plasticity in spinal lamina I projection neurons that mediate hyperalgesia. Science 299:1237-1240.

Kamiya H, Ozawa S, Manabe T (2002) Kainate receptor-dependent shortterm plasticity of presynaptic $\mathrm{Ca}^{2+}$ influx at the hippocampal mossy fiber synapses. J Neurosci 22:9237-9243.

Kerchner GA, Wilding TJ, Li P, Zhuo M, Huettner JE (2001) Presynaptic kainate receptors regulate spinal sensory transmission. J Neurosci 21:59-66.

Labrakakis C, Tong CK, Weissman T, Torsney C, MacDermott AB (2003) Localization and function of ATP and GABAA receptors expressed by nociceptors and other postnatal sensory neurons in rat. J Physiol (Lond) 549:131-142.

Lee CJ, Bardoni R, Tong CK, Engelman HS, Joseph DJ, Magherini PC, MacDermott AB (2002) Functional expression of AMPA receptors on central terminals of rat dorsal root ganglion neurons and presynaptic inhibition of glutamate release. Neuron 35:135-146.

Liu H, Wang H, Sheng M, Jan LY, Jan YN, Basbaum AI (1994) Evidence for presynaptic $N$-methyl-D-aspartate autoreceptors in the spinal cord dorsal horn. Proc Natl Acad Sci USA 91:8383-8387.

Liu H, Mantyh PW, Basbaum AI (1997) NMDA-receptor regulation of substance $P$ release from primary afferent nociceptors. Nature 386:721-724.

Lovinger DM, Weight FF (1988) Glutamate induces a depolarization of adult rat dorsal root ganglion neurons that is mediated predominantly by NMDA receptors. Neurosci Lett 94:314-320.

Lu CR, Hwang SJ, Phend KD, Rustioni A, Valtschanoff JG (2003) Primary afferent terminals that express presynaptic NR1 in rats are mainly from myelinated, mechanosensitive fibers. J Comp Neurol 460:191-202.

Ma QP, Hargreaves RJ (2000) Localization of N-methyl-D-aspartate NR2B subunits on primary sensory neurons that give rise to small-caliber sciatic nerve fibers in rats. Neuroscience 101:699-707.

Marvizon JC, Martinez V, Grady EF, Bunnett NW, Mayer EA (1997) Neurokinin 1 receptor internalization in spinal cord slices induced by dorsal root stimulation is mediated by NMDA receptors. J Neurosci 17:8129-8136.

Marvizon JC, McRoberts JA, Ennes HS, Song B, Wang X, Jinton L, Corneliussen B, Mayer EA (2002) Two $N$-methyl-D-aspartate receptors in rat dorsal root ganglia with different subunit composition and localization. J Comp Neurol 446:325-341.

Momiyama A (2000) Distinct synaptic and extrasynaptic NMDA receptors identified in dorsal horn neurones of the adult rat spinal cord. J Physiol (Lond) 523:621-628.

Monyer H, Burnashev N, Laurie DJ, Sakmann B, Seeburg PH (1994) Developmental and regional expression in the rat brain and functional properties of four NMDA receptors. Neuron 12:529-540.

Nicoll RA (1979) Dorsal root potentials and changes in extracellular potassium in the spinal cord of the frog. J Physiol (Lond) 290:113-127.

Pittaluga A, Raiteri M (1990) Release-enhancing glycine-dependent presynaptic NMDA receptors exist on noradrenergic terminals of hippocampus. Eur J Pharmacol 191:231-234.

Russo RE, Delgado-Lezama R, Hounsgaard J (2000) Dorsal root potential produced by a TTX-insensitive micro-circuitry in the turtle spinal cord. J Physiol (Lond) 528:115-122.

Sato K, Kiyama H, Park HT, Tohyama M (1993) AMPA, KA and NMDA receptors are expressed in the rat DRG neurones. NeuroReport 4:1263-1265.

Schmitz D, Mellor J, Nicoll RA (2001) Presynaptic kainate receptor mediation of frequency facilitation at hippocampal mossy fiber synapses. Science 291:1972-1976.

Segev I (1990) Computer study of presynaptic inhibition controlling the spread of action potentials into axon terminals. J Neurophysiol 63:987-998.

Thompson CL, Drewery DL, Atkins HD, Stephenson FA, Chazot PL (2002) Immunohistochemical localization of $N$-methyl-D-aspartate receptor subunits in the adult murine hippocampal formation: evidence for a unique role of the NR2D subunit. Brain Res Mol Brain Res 102:55-61.

Vesselkin NP, Adanina VO, Rio JP, Reperant J (2003) Ultrastructural study of glutamate- and GABA-immunoreactive terminals contacting the primary afferent fibers in frog spinal cord. A double postembedding immunocytochemical study. Brain Res 960:267-272.

Waddell PJ, Lawson SN (1990) Electrophysiological properties of subpopulations of rat dorsal root ganglion neurons in vitro. Neuroscience 36:811-822.

Willis WD, Coggeshall RE (1991) Sensory mechanisms of the spinal cord, Chap 4, pp 79-148. New York: Plenum. 